\title{
EVALUATION OF PHYSICAL AND MECHANICAL PROPERTIES OF COTTON WARPS UNDER A CYCLIC LOAD OF STRETCH-ABRASION
}

\author{
Min Guo, Jianli Liu, Bo Zhu, Weidong Gao* \\ Jiangsu Engineering Technology Research Center for Functional Textiles, Jiangnan University, Wuxi, China, 214122 \\ *Corresponding Author: e-mail: gaowd3@163.com.
}

\begin{abstract}
:
The fatigue behavior of cotton warps was studied by a newly weaving load simulator (WLS) developed in our laboratory. Reborn hairiness, strength retention, and elongation retention of sized warps were adopted to evaluate the physical and mechanical properties of sized warps under stretch-abrasion cyclic loading. The influences of different fatigue cycles on the above three indicators were also discussed. The results indicated that the fatigue behavior of the cotton warps accompanied by abrasion yields a three-parameter Weibull distribution. All the fitting plots show acceptable linearity. Moreover, there is a strong relationship of quadratic polynomial between the tensile properties and the fatigue cycle of the sized warps according to the scatter fitting $\left(R^{2}>91.08 \%\right)$. Similarly, there is also a good relationship of quadratic polynomial between the reborn hairiness index and the fatigue cycle of the sized warps $\left(R^{2}>94.51 \%\right)$. Finally, regardless of the strength retention, elongation retention, and reborn hairiness, the physical and mechanical properties of the cotton warps still change with the continuous increase of the fatigue cycle after $40 \%$ of the fatigue cycle, but it is not significant. The research was helpful to estimate the capacity of the warps to sustain failure.
\end{abstract}

\section{Keywords:}

Fatigue cycle, three-parameter Weibull distribution, physical and mechanical properties

\section{Introduction}

The service performance of sized warps is mainly the fatigue characteristic of yarns, obviously affecting the appearance and properties of the fabric and consequently influencing the production efficiency. The property of sized yarns has proved a certain correlation with warp stop. The fatigue resistance of sized warps primarily depends on the properties of fiber component, spinning technology, sizing agent, chemical treatment technology, and weaving environment [1-3]. The tensile failure mechanism, under cyclic stretching, bucking, and axial abrasion, of yarns has been extensively studied by many researchers. Das worked on the tensile and abrasion behavior of blended spun yarn made on different spinning technologies [4]. However, Behera et al. studied the mechanical properties (such as cohesion power, adhesion power, abrasion resistance, and bending rigidity) of size films along with the weaving performance of the sized yarn [5]. Mokhtari et al. and Behera et al. reported on the fatigue fracture mechanism of yarn using a technique of digital image analysis [6, 7]. Seung et al. and Mishra et al. investigated the mechanical properties and abrasion behavior of yarn in fabric form [8, 9]. However, representing the fatigue characteristics of yarn based on the failure criterion in terms of only the fatigue cycle is not enough. The rate of fatigue damage expressed in terms of loss in tensile property indicators has also proven to be useful in assessing the fatigue-sustaining capacity of yarn and thereby predicting impending failure. Furthermore, the relevant literature on the characterization of physical and mechanical properties of sized warps under tensile fatigue loading is scarce, considering various factors.

The relationship between the fatigue cycles, loss in tensile properties, and gain in the physical properties of sized yarns must be balanced. Therefore, in this research, the effects of the fatigue cycle on strength retention (SR), elongation retention (ER), and reborn hairiness $(\mathrm{RH})$ of sized warps by the WLS developed in our laboratory have been studied. To study the effect of the fatigue action on the tensile properties and physical characteristics of the sized warps, a detailed analysis was also performed. Besides, the failure characteristic of cotton warps was studied based on a three-parameter Weibull distribution. These findings not only presented the actual fatigue state and process of warps worn by a WLS but also better clarified the changes in the physical and mechanical properties of sized warps under a cyclic mechanic load. It was helpful to develop sized warps with higher weaving performance and estimate the capacity of the warps to sustain failure. Besides, the design of WLS comprehensively takes into account the fatigue characteristics of the yarn under a cyclic load of stretch abrasion. 


\section{Experiments and methods}

\subsection{Yarn preparation}

The specimens used in this study were cotton compact spun yarns in common use, and a total of four specimens were selected to compare with the physical and mechanical properties. The specifications of the specimens are shown in Table 1.

\subsection{Fatique cycle test}

The fatigue cycle tests of warps were conducted using the WLS developed in our laboratory. Figure 1 presents the schematic diagram of the simulator. One end of the warp was fixed to the pre-tension weight, and the other end passed through the splitting roller, and then through the drop and induction device, smooth roll, reciprocating friction roll, and the oscillating friction roll. The reciprocating friction roll imparted flex abrasion and cyclic stresses to yarn. The oscillating friction roll imparted only flex abrasion to yarn. During the test, the reciprocating friction roll and the oscillating friction roll reciprocated once, and they produced a tensile, friction, and buckling effect on the yarn. The internal counter of the simulator recorded the fatigue cycle once. The number of cycles required to break yarn in trials was the index of the fatigue cycle. Besides the deflection, characteristics of the friction roll such as its surface roughness and material size and shape may also affect fatigue resistance.

The testing parameters of the WLS including the load amplitude, load speed, and pre-tension were set to $70 \mathrm{~mm}, 180 \mathrm{cycle} / \mathrm{min}$, and $2.1 \mathrm{cN} /$ tex, respectively. The temperature and the relative humidity were $(20 \pm 3)^{\circ} \mathrm{C}$ and $(65 \pm 5) \%$, respectively.

\subsection{Tensile properties test}

To investigate the effect of the fatigue test on the tensile properties, the sized warps were worn for a certain number of cycles on the WLS equal to $5,10,20,40$, and $80 \%$ of their fatigue cycles tested based on failure. The warps that survived after the above-mentioned fatigue levels were collected and the tensile properties were further measured using an electronic single yarn strength tester model SHIMADZU AGS-X according to $G B / T$ 3916-1997 with $250 \mathrm{~mm} / \mathrm{min}$ speed and $250 \mathrm{~mm}$ specimen length. Thirty tests were conducted for each sample

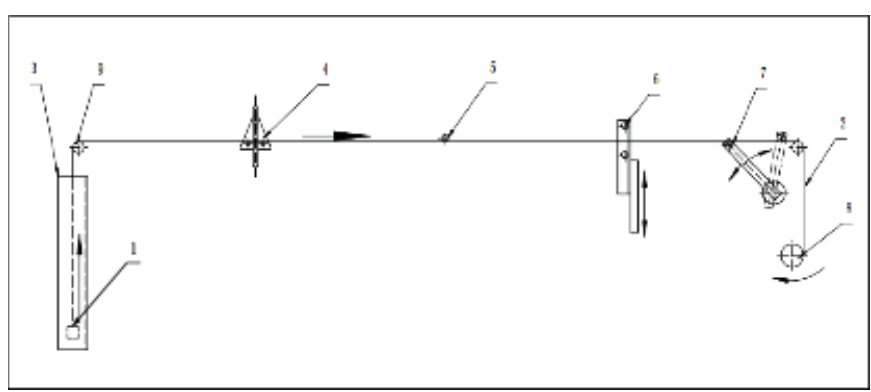

Figure 1. Schematic diagram of the simulator. (1) pre-tension weight; (2) yarn; (3) weight slot; (4) dropper and induction device; (5) smooth roll; (6) reciprocating friction roll; (7) oscillating friction roll; (8) the winding roll; and (9) the splitting roll.

and the mean values were acquired. The temperature and the relative humidity were $(20 \pm 3)^{\circ} \mathrm{Cand}(65 \pm 5) \%$, respectively. Equations (1) and (2) show the calculation of SR and ER, respectively. They are defined as follows:

$S R=\frac{S_{1}}{S_{0}} \times 100 \%$

$E R=\frac{E_{1}}{E_{0}} \times 100 \%$

where $\mathrm{SR}$ is the strength retention in $\%, S_{1}$ is the breaking strength of worn warp in $\mathrm{cN}$, and $S_{0}$ is the breaking strength of unworn warp in cN; ER is the elongation retention in $\%, E_{1}$ is the elongation at break of worn warp in millimeter, and $E_{0}$ is the elongation at break of unworn warp in millimeter.

\subsection{Reborn hairiness test}

The $\mathrm{RH}$ of warps causes the warp ends to cling together and even break off when weaving. Particularly critical is $\mathrm{RH}$ in staple fibers when they are woven on air-jet looms. Therefore, $\mathrm{RH}$ is an important parameter to evaluate the physical property of warps after fatigue load. The WLS was developed for abrading yarn. In this article, specimens endured different fatigue cycles to examine the development of $\mathrm{RH}$. The abrasion areas of the worn warps are marked and obtained. We used a yarn examine machine model YG381 manufactured by Nantong Hongda Experimental Instrument Co. LTD (Nantong, China) to wind the worn warps evenly on it. The scanner model 9000F Mark2 manufactured by Canon China Co. LTD (Shanghai, China)

Table 1. Yarn specification

\begin{tabular}{|c|c|c|c|c|c|c|c|c|c|c|}
\hline \multirow{2}{*}{$\begin{array}{c}\text { Linear } \\
\text { density } \\
\text { (tex) }\end{array}$} & \multicolumn{9}{|c|}{ Unsized yarn } & \multicolumn{4}{c|}{ Sized yarn } \\
\cline { 2 - 11 } & $\begin{array}{c}\text { Twist } \\
\text { level }\end{array}$ & $\begin{array}{c}\text { Twist } \\
\text { level } \\
\text { (Tw } \\
(\%)\end{array}$ & $\begin{array}{c}\text { Breaking } \\
\text { strength } \\
(\mathbf{c N})\end{array}$ & $\begin{array}{c}\text { Breaking } \\
\text { strength } \\
\text { CV } \\
(\%)\end{array}$ & $\begin{array}{c}\text { Breaking } \\
\text { elongation } \\
(\%)\end{array}$ & $\begin{array}{c}\text { Breaking } \\
\text { elongation } \\
\text { CV } \\
(\%)\end{array}$ & $\begin{array}{c}\text { Breaking } \\
\text { strength } \\
(\mathbf{c N})\end{array}$ & $\begin{array}{c}\text { Breaking } \\
\text { strength } \\
\text { CV (\%) }\end{array}$ & $\begin{array}{c}\text { Breaking } \\
\text { elongation } \\
(\%)\end{array}$ & $\begin{array}{c}\text { Breaking } \\
\text { elongation } \\
\text { CV (\%) }\end{array}$ \\
\hline 19.4 & 723.8 & 3.09 & 302.73 & 12.19 & 3.77 & 12.31 & 401.62 & 7.96 & 2.87 & 16.50 \\
\hline 14.5 & 736.6 & 3.05 & 257.38 & 7.72 & 4.52 & 17.64 & 369.63 & 7.56 & 3.31 & 10.78 \\
\hline 11.6 & 953.2 & 4.57 & 193.45 & 7.25 & 3.85 & 11.79 & 318.72 & 8.36 & 3.41 & 14.49 \\
\hline 9.7 & 1002.3 & 2.78 & 187.74 & 6.19 & 3.95 & 34.26 & 262.73 & 10.05 & 3.15 & 14.23 \\
\hline
\end{tabular}


provided a digital image of yarn. Finally, the images were processed, and the hairiness area index was extracted from them by the developed program through MATLAB R2014b [10]. A total of 30 tests were conducted for each sample. The mean values and the coefficient of variation (CV) acquired were used as data. The hair area index $\left(H\right.$ and $\left.H_{1}\right)$ was recorded. Hair area index $\left(H\right.$ or $\left.H_{1}\right)$ is a unit-less parameter defined as a ratio between the total area of single (i.e. looped and protruding) fibers $S_{F}$ or $S_{F 1}$ and the total area of core $S_{C}$ [11]. It can be expressed by the following equation:

$H=\frac{S_{F}}{S_{C}} \times 100 \%$

$H_{1}=\frac{S_{F 1}}{S_{C}} \times 100 \%$

where $H$ is the total hair area index in $\%, S_{F}$ is the total area of single fibers, $S_{C}$ is the total area of the core; $H_{1}$ is the hair (3 $\mathrm{mm}$ or longer) area index in\%, and $S_{\mathrm{F} 1}$ is the area of single fibers ( $3 \mathrm{~mm}$ or longer).

\subsection{Statistical analysis}

The influence of linear density on the statistical distribution of the yarns' fatigue characteristic was investigated by the Weibull distribution. The collected data on SR, ER, and RH were analyzed statistically by a scatter plot. Regression fitting and $R^{2}$ were used to determine whether a response was significantly influenced by the independent parameters.

The behavior of Yarn fatigue follows a three-parameter Weibull distribution [12], which is given in Equation (5) as follows:

Table 2. Weibull parameters of unsized yarn

Table 2. Weibull parameters of unsized yarn
\begin{tabular}{|c|c|c|c|c|c|c|c|c|}
\hline & Groups & Location/Y & Shape/ $\boldsymbol{\beta}$ & Scale/n & Dn & Mean & STDEV.P & CV \\
\cline { 2 - 9 } & 19.4 tex-S1 & 128 & 3.05 & 871.53 & 0.102 & 792.4 & 229.23 & $28.92 \%$ \\
\cline { 2 - 9 } Unsized yarn & 14.5 tex-S2 & 40 & 2.70 & 839.91 & 0.090 & 751.4 & 250.85 & $33.38 \%$ \\
\cline { 2 - 9 } & 11.6 tex-S3 & 134 & 3.85 & 605.22 & 0.218 & 560.2 & 138.42 & $24.71 \%$ \\
\cline { 2 - 9 } & 9.7 tex-S4 & 92 & 3.26 & 508.45 & 0.102 & 465.3 & 126.86 & $27.26 \%$ \\
\hline
\end{tabular}

Table 3. Weibull parameters of sized yarn

\begin{tabular}{|c|c|c|c|c|c|c|c|c|}
\hline & Groups & Location/Y $\square$ & Shape/ $\boldsymbol{\beta}$ & Scale/n $\square$ & Dn & Mean & STDEV.P & CV \\
\cline { 2 - 8 } Sized yarn & 19.4 tex-S5 & 162 & 2.81 & 1153.55 & 0.106 & 1045.1 & 309.36 & $29.60 \%$ \\
\cline { 2 - 8 } & 14.5 tex-S6 & 210 & 2.53 & 1063.43 & 0.140 & 967.5 & 269.60 & $27.86 \%$ \\
\cline { 2 - 9 } & 11.6 tex-S7 & 145 & 3.10 & 813.05 & 0.172 & 742.5 & 205.36 & $27.65 \%$ \\
\cline { 2 - 9 } & 9.7 tex-S8 & 123 & 3.33 & 781.46 & 0.070 & 714.0 & 199.72 & $27.97 \%$ \\
\hline
\end{tabular}

where $P(t)$ is the probability of cumulative fatigue; $t$ is the lifetime in the number of cycles to rupture; $\gamma$ is the minimum lifetime that the yarn will survive in; $\eta$ and $\beta$ are Weibull scale and shape parameter, respectively. $\beta$ decides the shape of the distribution. $P$ is calculated by $(i-0.3) /(N+0.4)$ [13], where $N$ is the total sample size and $i$ is the ranking of a test based on the fatigue cycle data stored in ascending order.

a linear form.

$\ln \left[\ln \left(\frac{1}{1-P}\right)\right]=\beta \ln (t-\gamma)-\beta \ln \eta$

To evaluate the Weibull distribution model, a one-sample Kolmogorov-Smirnov (K-S) test was applied at a commonly adopted significance level $(\alpha=0.01)$. The procedure of the goodness-of-fit test is as follows:

1. Determine the maximum deviation $\left(D_{n}\right)$ between $P_{0}$ from $P_{0}=(i-0.3) /(N+0.4)$ and $P$ from the Weibull probability (Equation 5).

$D_{n}=\max \left|P_{0}-P\right|$

2. The critical value $D_{\mathrm{nc}}$ can be obtained from the $\mathrm{K}-\mathrm{S}$ test table. For $N=50$ and a significance level of $\alpha=0.01$,

$D_{n c}=\frac{1.63}{\sqrt{N}}$ 
3. If $D_{\mathrm{n}}<D_{\mathrm{nc}}$, the Weibull distribution model is considered as a significant fit to the observed distribution.

The fitting of the Weibull distribution model is effective, and the mean value and variance of Weibull distribution can be

$$
\begin{aligned}
& \mu=\gamma+(\eta-\gamma) \Gamma\left(1+\frac{1}{\beta}\right) \\
& S=(\eta-\gamma)\left[\Gamma\left(1+\frac{1}{\beta}\right)-\Gamma^{2}\left(1+\frac{1}{\beta}\right)\right]^{\frac{1}{2}}
\end{aligned}
$$

where $\Gamma(x)$ - - is the gamma function, which can be obtained by looking up the table.

\section{Results and discussion}

\subsection{Fatique characteristic}

The fatigue characteristics of the yarn accompanied by strength and abrasion are of great importance for the weavability of warp. The Weibull distribution parameters of unsized and sized yarn samples in this article are given in Tables 2 and 3 , respectively.

As for Figures 2(a) and 3(a), the Weibull statistical analysis of the fatigue cycle data yields three characteristic parameters for each group, that is, $\gamma, \beta$, and $\eta$. The results are summarized in Tables 2 and 3. The value of location parameter $y$ is the lower bound of the distribution, the minimum fatigue cycle that the yarn will survive [7]. The value of scale parameter $\eta$, which is the characteristic fatigue cycle and numerical close to the mean fatigue cycle, is found to be decreased with decreasing linear density irrespective of unsized and sized yarns. The shape parameter $\beta$ is related to the coefficient of variations. All the fitting plots show acceptable linearity $\left(R^{2}>0.919\right.$, except 11.6tex), signifying a reasonable Weibull distribution fitting. Furthermore, according to the values of $D_{n}$ using a onesample $\mathrm{K}-\mathrm{S}$ test, the fatigue cycle of the yarn at four different linear densities irrespective of unsized and sized yarns all fit the Weibull distribution well at a level of $1 \%$ : all the $D_{n}$ values are lower than that of the critical value $(0.2305)$. As is well known, the twist imparted to the yarn affects the structure of yarn and the mechanical properties of the yarn. In automatic weaving, warp twist would also affect end breakage rate and consequently weaving efficiency. In general, increasing the twist and thus reducing the amount of loosely bound fiber on the yarn surface materially reduced the number of failures due to this factor. This is obviously due to the consolidation of the fiber assembly on account of the increase in helix angle, which causes an improvement in resistance to inter-fiber slippage during weaving stress. The twist level and linear density effects on the fatigue cycle of yarns are apparent, and the corresponding fatigue can be reasonably predicted from the three-parameter Weibull distribution model. The cumulative failure probability model (Figures $2(b)$ and $3(b)$ ) is presented to predict the threshold values of the yarn fatigue cycle with different linear densities. All plots reveal a similar upward trend with increasing fatigue level, and yarns with different linear densities have different threshold values, which is a distinct indicator of the linear density dependence of the fatigue cycle. Therefore, the effect of linear density on the fatigue cycle cannot be ignored.

It can be also seen from Figure 2 that Weibull plots lie toward the far right of the plots for the yarn of 19.4 tex, followed by $14.5,11.6$, and 9.7 tex from right to left. This indicates the optimal fatigue property of the yarns of 19.4 tex as compared to that of the other three yarns, owing to the highest resistance to fatigue accompanied by stretch and abrasion. The higher the linear density of the yarn, the greater the number of fibers in the cross-section of yarn, and the harder it is to make it a failure. Nevertheless, after sizing, the improvement obtained in the weaving potential of yarn is substantially higher irrespective of linear density. These yarns exhibit similar trends after sizing, which are shown in Figure 3. Thus, it can be concluded that the fatigue characteristic of the yarn plays a dominant role in determining the weaving performance even in sized yarns.

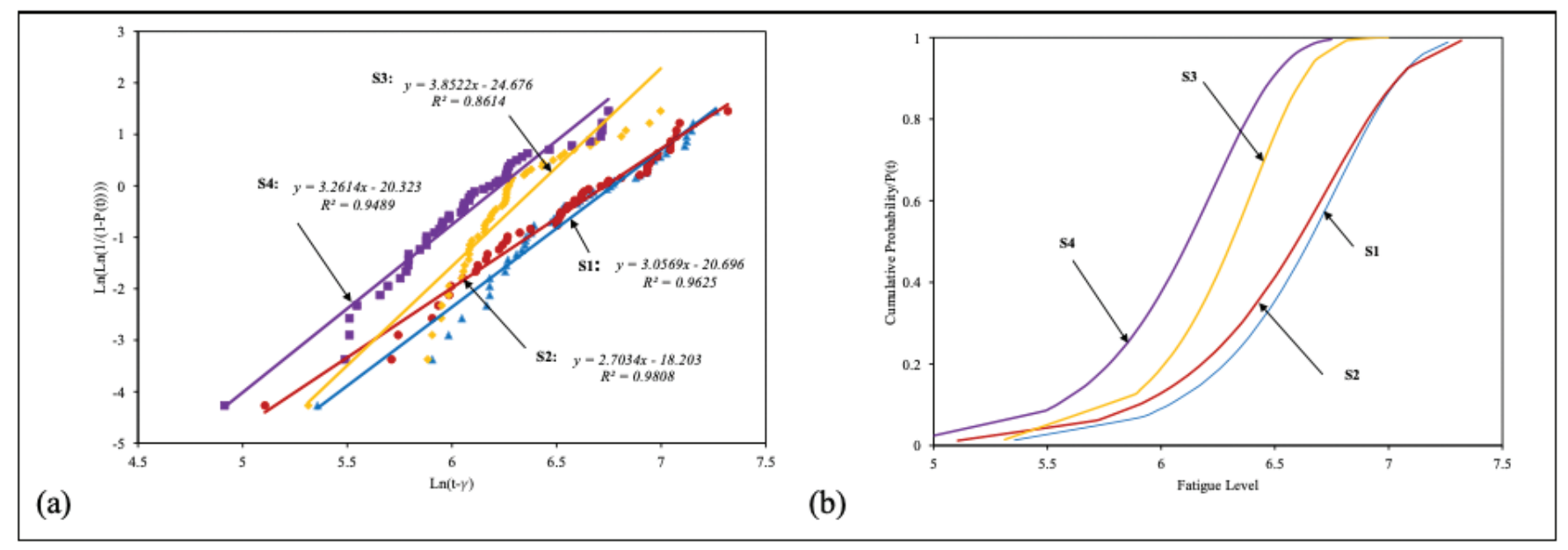

Figure 2. Weibull distribution model of unsized yarns with different linear densities: (a) Weibull distribution plots and fitting evaluation and (b) cumulative failure model. 


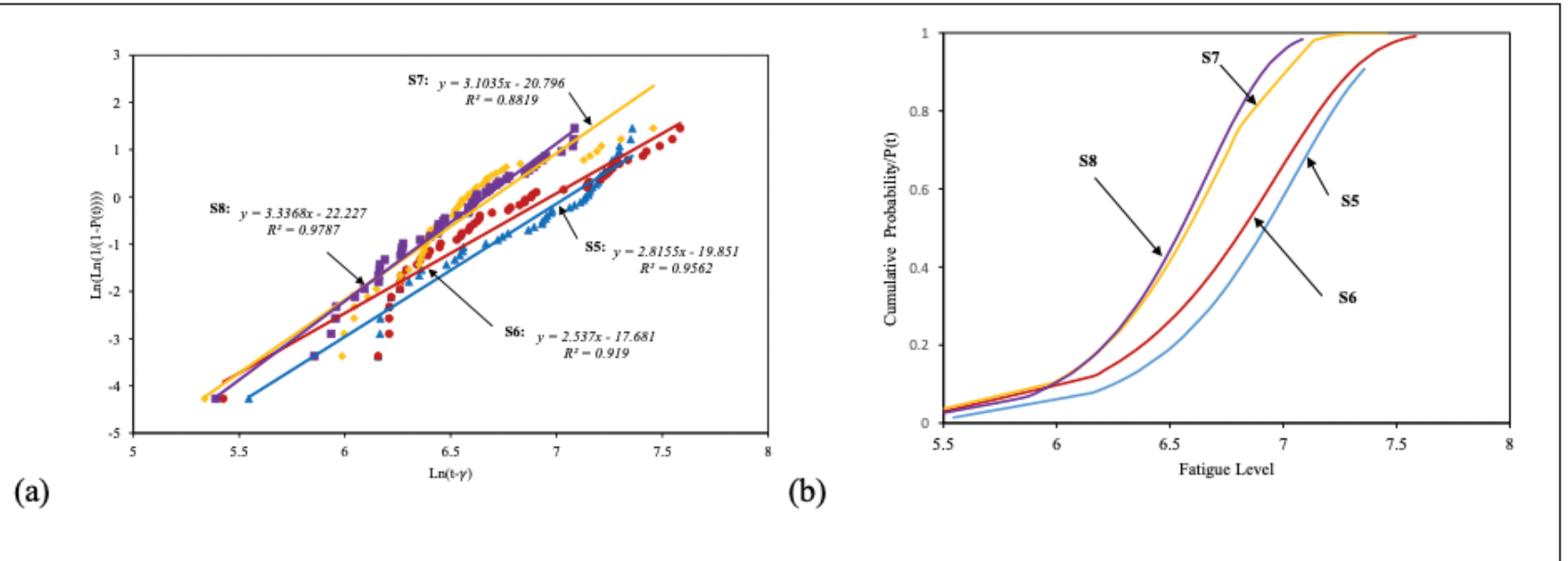

Figure 3. Weibull distribution model of sized yarns with different linear densities: (a) Weibull distribution plots and fitting evaluation and (b) cumulative failure model.

\subsection{Tensile properties}

Although the fatigue characteristic of yarn is of great importance for the warps, it is hard enough to establish weaving potential in terms of the characteristic fatigue cycle calculated by fitting a Weibull distribution because the actual tensile fatigue cycles of the yarn imposed on a loom can sometimes be far lower than these characteristic fatigue cycles. Therefore, understanding the gradual deterioration of yarn tensile properties as fatigue levels increase may yield useful information about the potential failure of yarn. Moreover, the breaking strength and breaking elongation of a warp are reduced by about $10 \%$ after weaving [14]. SR of a warp was a parameter that can reflect the ability to avoid damage from failure $[15,16]$. In this experiment, with four sized yarn of different linear densities, the relationship between the SR and fatigue cycles as well as between ER and fatigue cycles was studied.

The variations in SR and ER with four sized warps of different linear densities are shown in Figure 4. As can be shown, both the SR and ER decrease generally with increasing fatigue cycles, as expected. Figure 4(a) shows that the SRs drop slightly in the first $5 \%$ of fatigue cycles, especially for 14.5 tex yarn from $100 \%$ to $96.73 \%$. This may be explained as follows. At the initial testing stage, a small amount of the size coating gets abraded, residual surface slurry maintained the structural integrity of warp and played a role in protecting fibers. Therefore, the reduction of yarn strength is not obvious. With the test progressing, the surface slurry was gradually worn off, and the exposed sheath fibers were worn directly by the load component. Cracks occurred on the surface of fibers and they damaged the structural integrity of the warps, which resulted in a decrease in the tensile properties [17]. Thus, the SR of yarns steadily declines from $100 \%$ to below $90.09 \%$ in the first $10 \%$ of fatigue cycles, except 14.5 tex yarn. Figure 4 (a) also demonstrated that SR declined significantly from $20 \%$ to $40 \%$ of the fatigue cycle. The reason is that the warp was always kept in close contact with the load component and damaged after being worn for a certain amount of cycles. Once the relative movement between the warp and the load component occurred, the repetitive load between sheath fibers of warp and the load component would greatly reduce the cross-section and lead to a sharp decrease in tensile properties of warp [18, 19]. Moreover, in each fatigue cycle of the test, the testing area of warp alternated between straight and curved conditions, which caused bending and tensile fatigue. The indicator of ER shows a similar tendency, as shown in Figure 4(b). The results also reveal that the SR and ER of the yarn do not continuously decrease with increasing fatigue cycles but reach a threshold value at a $40 \%$ of fatigue cycle, after which they start to decline slowly. The authors observed a similar trend for cotton yarns

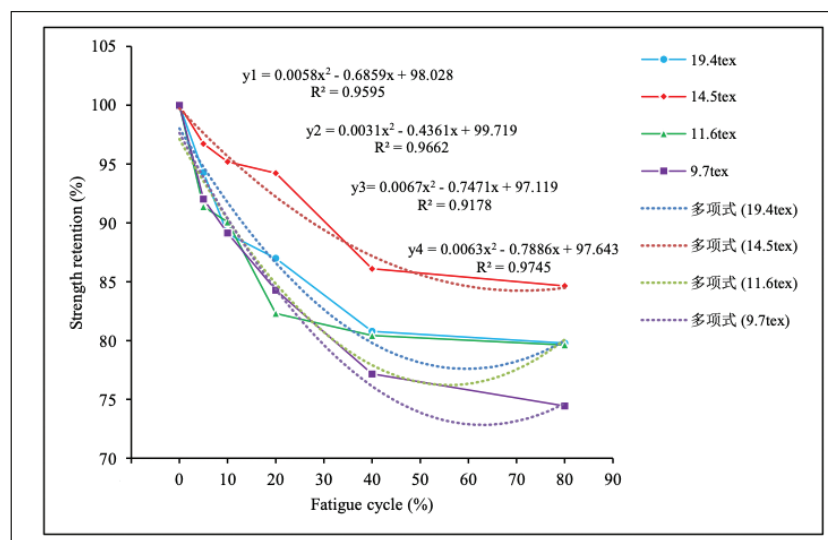

(a)

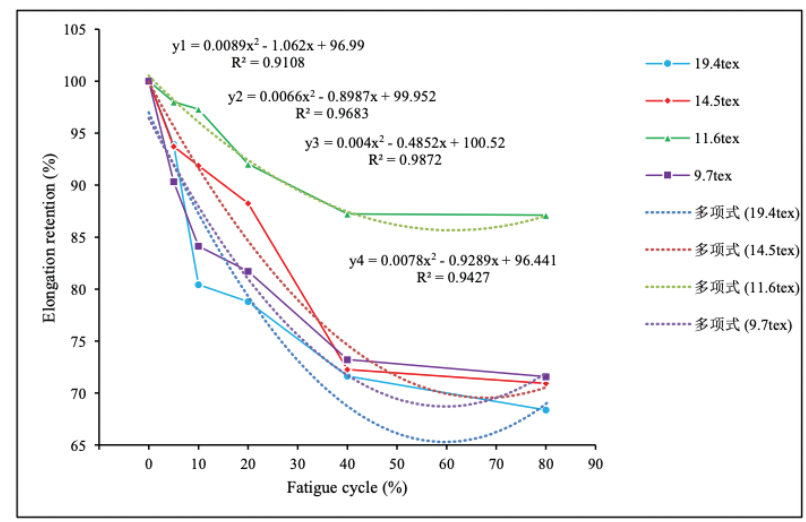

(b)

Figure 4. Relationship between strength retention and elongation retention of worn warps. (a)Strength retention of worn warps with different linear densities and (b) elongation retention of worn warps with different linear densities. 
$[2,6,20]$. Figure 4 also demonstrates a very strong relationship of quadratic polynomials between the tensile property and the fatigue cycle. The results of $R^{2}$ are all within the acceptable range. Therefore, in practical applications, the critical issue

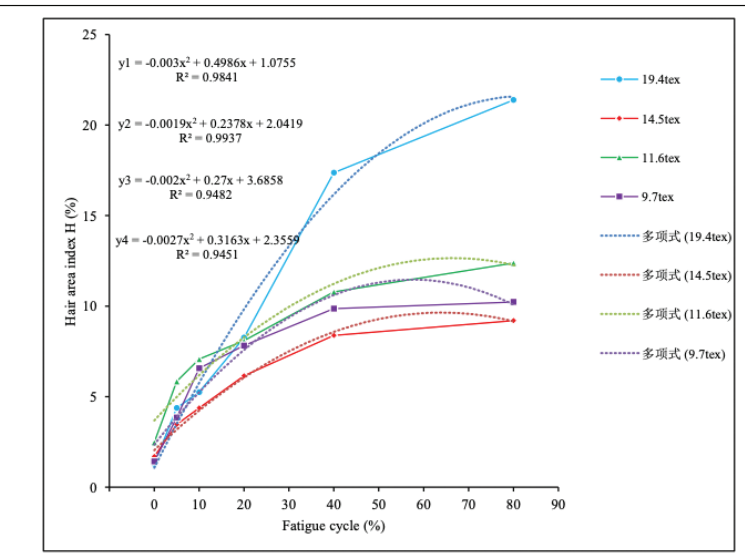

(a)

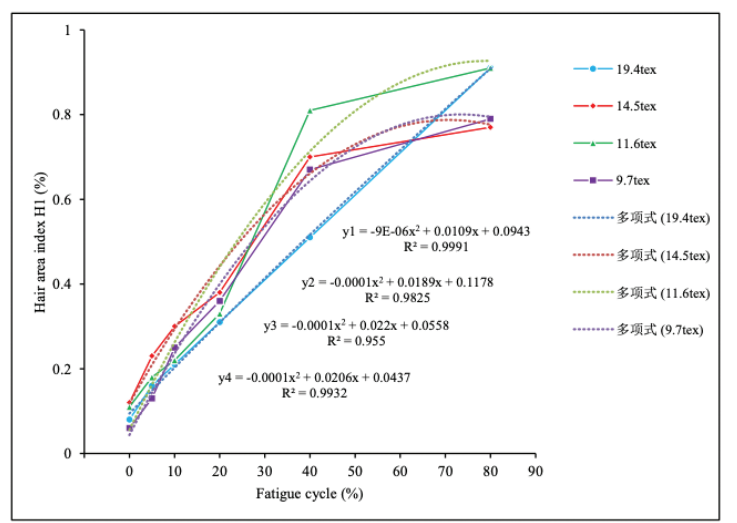

(b)

Figure 5. Relationship between reborn hairiness and the fatigue cycle. (a) Hair area index $\mathrm{H}$ of different fatigue cycles and (b) hair area index $\mathrm{H}_{1}$ of different fatigue cycles. is to improve the surface performance of warp to reduce the influence of abrasion and stretch on its mechanical properties.

\subsection{RH and morphology observation}

|The $\mathrm{RH}$ of yarn is an important index to evaluate the physical performance of yarn. Reducing the $\mathrm{RH}$ generated during weaving can effectively avoid end-breakage caused by the adhesion between adjacent warps. The relationships between fatigue cycle and hair area index as well as between the fatigue cycle and hair area index ( $3 \mathrm{~mm}$ or longer) are shown in Figure 5. According to the experimental results and observed morphology, typical images of worn warps at various fatigue cycles were obtained, as shown in Table 4.

As can be seen in Figure 5, under different fatigue cycles, $H$ and $H_{1}$ indicate that the $\mathrm{RH}$ increases slightly with an increasing fatigue cycle in the first $5 \%$ of fatigue cycles for all samples mentioned above. This may be explained as follows. First, a thin layer of the size coating is abraded, the friction component had worn off the surface of sheath fibers and exposing surface fibers of yarns to abrasion to generate a small amount of hairiness. Similarly, $\mathrm{RH}$ has been found to increase gradually with the increase of the fatigue cycle from $5 \%$ to $20 \%$. The presence of worn warp gradually progressed from slightly fuzzy to rough in this stage. Nevertheless, plucking of fibers from the yarn body due to cycle abrasion and stretch is likely to create higher $\mathrm{RH}$ in the sheath between $20 \%$ and $40 \%$ of the fatigue cycle. Therefore, the $\mathrm{RH}$ is almost twice the amount suffered by up to $40 \%$ of the fatigue cycle. It is especially obvious for the $H$ of 19.4 tex yarn. There is a small amount of hairiness nodules to form hairballs as shown in Table 4. During the last testing stage, the uptrends of $\mathrm{RH}$ are moderate between $40 \%$ and $80 \%$ of the fatigue cycle. The reason is to be that with the continuous expansion of the yarn core, the number of fibers projecting from the yarn surface to form hairiness is limited [21-23]. The warp was very fuzzy and more sheath fibers were damaged, and the

Table 4. Initial images and images after each fatigue cycle

\begin{tabular}{|c|c|c|c|c|}
\hline & 19.4tex & 14.5tex & 11.6tex & 9.7tex \\
\hline $0 \%$ & & & & \\
\hline $5 \%$ & & & & \\
\hline $10 \%$ & & & & \\
\hline $20 \%$ & & & & \\
\hline $40 \%$ & & & & \\
\hline $80 \%$ & & & & \\
\hline
\end{tabular}


structure of the warp became looser. Similarly, the relationship of quadratic polynomials between the hairiness area index and fatigue cycle fits well. The results of $R^{2}$ are almost all above $95.50 \%$. The uptrend of $\mathrm{RH}$ increasing with the fatigue cycle coincides with the downtrend of SR decreasing with fatigue life.

\section{Conclusions}

This article studied the physical and mechanical properties and fatigue characteristics of cotton warps. According to the experimental results and analysis, the following conclusions can be drawn.

(i) The fatigue behavior of cotton warps accompanied by abrasion yields a three-parameter Weibull distribution. All the fitting plots show acceptable linearity.

(ii) Fatigue action can significantly reduce the tensile properties and enhance the $\mathrm{RH}$ of sized warps. According to the scatter fitting, there are both strong relationships of quadratic polynomial between the tensile properties and the fatigue cycle of the sized warps as well as between the $\mathrm{RH}$ index and the fatigue cycle of the sized warps. The results of $R^{2}$ of all fitting models are almost above $95.50 \%$.

(iii) The physical and mechanical properties of the cotton warps still change with the continuous increase of the fatigue cycle beyond $40 \%$ of the fatigue cycle. Nevertheless, the changing trend is not significant.

\section{Acknowledgments}

The author would like to acknowledge funding from the Postgraduate Research \& Practice Innovation Program of Jiangsu Province (No. KYCX18_1831).

\section{References}

[1] Muhammad, M., Muhammad, I. K., Khubab, S., Muhammad, U., Yasir, N. (2017). Recycling of warp size materials and comparison of yarn mechanical properties sized with recycled materials and virgin materials. The Journal of The Textile institute, 108(1), 84-88.

[2] Faasen, N. J., Harten, K. V. (1966). The effect of sizing on the weavability of cotton yarns. Journal of the Textile Institute, 57 (7), 269-285.

[3] Brorens, P. H., Lappage, J., Bedford, J., Ranford, S. L. (1990). Studies on the abrasion-resistance of weaving yarns. The Journal of The Textile institute, 81(2), 126-134.

[4] Ishtiaque, S. M., Rengasamy, R. S., Das, B. R. (2014). Prediction of strength and weavability of blended spun yarns. Fibres and Polymers, 15(8), 1752-1757.

[5] Behera, B. K., Gupta, R., Mishra, R. (2008). Comparative analysis of mechanical properties of size film. I. Performance of individual size materials. Fibres and Polymers, 9(4), 481-488.
[6] Asgari, H., Mokhtari, F., Latifi, M., Amani-Tehran, M. (2014). Characterizing cotton yarn appearance due to yarn-to-yarn abrasion by image processing. The Journal of The Textile Institute, 105(5), 477-482.

[7] Behera, B. K., Joshi, V. K. (2006). Warp breakage mechanism of friction spun yarns. The Journal of the Textile Institute, 97(6), 503-512.

[8] Jeon, Y. H., Won, Y. J., Jung, W. P., Seung, K. A. (2003). The Mechanical properties and abrasion behavior of warp knitted fabrics for footwear. Fibres and Polymers, 4(4), 151-155.

[9] Rajesh, M., Hafsa, J., Jiri, M. (2017). Investigation of mechanical properties of basalt woven fabrics by theoretical and image analysis methods. Fibres and Polymers, 18(7), 1369-1381.

[10] Wang, J. A., Xu, B. G., Li, Z. J., Gao, W. D., Wang, L. (2018). Depth recovery of hairy fibers for precise yarn hairiness measurement. Applied Optics, 57(24), 7021 7029.

[11] Guha, A., Amarnath, C., Pateria, S., Mittal, R. (2009). Measurement of yarn hairiness by digital image processing. The Journal of The Textile Institute, 99(6), 1754-2340.

[12] Anandjiwala, R. D., Carmical, M., Goswami, B. C. (1995). Tensile properties and static fatigue behavior of cotton warp yarns. Textile Research Journal, 65(3), 131-149.

[13] Zhang, Y., Wang, X., Pan, N. (2002). Weibull analysis of the tensile behavior of fibers with geometrical irregularities. Journal of Materials Science, 37, 1401-1406.

[14]Zhao, Q. M. (2006). Investigation of physical and mechanical properties of sizing yarn before and after weaving. Journal of Donghua University, 32(4), 92-95.

[15] Flory, J. F. (1997, October). External abrasion testing of fiber ropes. MTS/IEEE Conference Proceedings (pp. 325330), In Canada.

[16] Mccorkle, E., Chou, R., Stenvers, D. (2003, September). Fatigue and residual strength of fiber tuglines. OCEANS 2003 Proceedings (pp.1058-1063), In the USA.

[17] Frank, F., Singleton, R. W. (1964). A study of factors influencing the tensile fatigue behavior of yarns. Textile Research Journal, 34(1), 11-19.

[18] Das, B. R., Ishtiaque, S. M., Rengasamy, R. S., Hati, S. (2011). Prediction of weavability of warp yarns: A critical review. Research Journal of Textile and Apparel, 15(3), 3849.

[19] Xie, K. F., Xu, Y. F., Shen, H., Xu, G. B. (2018). Study on the wearability and abrasion mechanism of braided harness cord. Textile Research Journal, 89(14), 2961-2969.

[20] Anandjiwala, R. D., Goswami, B. C. (1995). Tensile fatigue behavior of staple yarns. Textile Research Journal, 63(7), 392-403.

[21] Friedman, H. L., Bernard, M., Rudolph, T. (1985). Laboratory evaluation of sized warp yarn performance, Accelerated Wear and Hairiness. Textile Chemist \& Colorist, 17(5), 88-94.

[22] Friedman, H. L., Zhou, Y. Y., Bernard, M. (1989). Development of hairiness of sized warp yarns during flexabrasive wear. Textile Research Journal, 59, 495-500.

[23] Trauter, J., Gotz, K. (1983). Measures to reduce hairiness in sizing. Melliand Textilber, 12, 402-408. 